\title{
Cerebrospinal Fluid and Ependymal Neurophysin
}

\author{
Alan G. Robinson and Earl A. Zimmerman \\ From the Department of Medicine, University of Pittsburgh School of \\ Medicine, Pittsburgh, Pennsylvania 15261, and the Department of Neurology, \\ College of Physicians and Surgeons, Columbia University, New York 10032
}

\begin{abstract}
A B S T R A C T Neurophysins are "carrier proteins" associated with vasopressin and oxytocin in the neurohypophyseal system. The release of these hormone associated proteins may serve as an indicator of posterior pituitary function. This report describes the measurement of neurophysin in human and monkey plasma and cerebrospinal fluid (CSF) by radioimmunoassay. Tissue neurophysin is also localized in monkey brain by the immunoperoxidase technique. CSF from 68 patients and five monkeys had easily measurable neurophysin in every sample. The concentration of neurophysin in CSF and in plasma of man is $5.4 \pm 0.30 \mathrm{ng} / \mathrm{ml}$ (mean and SEM) and $0.69 \pm 0.04$, respectively. The two means were significantly different $(P<0.001)$. In paired plasma and CSF specimens which were obtained simultaneously from each of 13 human and five monkey donors, the concentrations of neurophysin in CSF were greater than those of plasma in every case (paired $t$ test, $P<0.001$ ). Neurophysin administered intravenously to dogs did not enter CSF. Using the immunoperoxidase technique, we found neurophysin not only in the supraoptic and paraventricular nuclei, their tracts, and the posterior pituitary, but also in the specialized ependymal tanycytes of the infundibular recess of the third ventricle and in the external layer of the median eminence where capillaries drain into hypophyseal portal vessels. Neurophysin may pass from CSF to portal vessels via tanycytes in a manner similar to that postulated for releasing factors.
\end{abstract}

\section{INTRODUCTION}

Neurophysins are proteins synthesized in the supraoptic and paraventricular nuclei of the hypothalamus in association with the octapeptide hormones, vasopressin and oxytocin $(1,2)$. Neurophysins are thought to be "carrier

Dr. Zimmerman is the recipient of Teacher-Investigator Award NS 11,008 from the National Institute of Neurological Diseases and Stroke.

Received for publication 16 October 1972 and in revised form 12 January 1973.

1260 The Journal of Clinical Investigation Volume 52 May 1973·1260-1267 proteins" for these peptide hormones, and recent evidence obtained in cows, pigs, rats, goats, and man (3-7) has confirmed earlier suggestions that neurophysins may be released into the bloodstream in association with oxytocin and vasopressin. Anatomic studies have indicated that there may be one neurophysin for oxytocin and another for vasopressin $(8,9)$. However, such an association may not be absolute as indicated by the existence of a third neurophysin in some animals $(10,11)$ and by limited physiologic data in the cow (3). Nonetheless, a study of neurophysin localization in hypothalamic tissue and neurophysin secretion may provide new insight into the function of the neurohypophyseal system.

Controversy about the secretion of neurohypophyseal hormones into cerebrospinal fluid (CSF), ${ }^{1}$ as recently reviewed by Heller (12), has prompted a search for neurophysin in CSF. Data derived by bioassays has produced conflicting results on the presence of oxytocin and vasopressin in CSF. Although early investigators found oxytocic and antidiuretic activities in CSF, these findings were later discounted when Van Dyke (13) drew attention to ionic and other properties of CSF that might lead to artifactual results. However, recent studies using improved bioassays indicated that vasopressin and oxytocin are present in spinal fluid (14-16). It is unresolved as to whether these hormones are secreted directly into the CSF or are transferred to CSF from peripheral plasma. Studies reported here on neurophysin in CSF offer support for a direct secretion of neurohypophyseal peptides into CSF.

Having identified neurophysin in CSF, we utilized our experience with tissue localization of neurophysin to search for a ventricular point of entry or exit. We have previously demonstrated that specific antibodies to neurophysin localize neurophysin in the neurohypophyseal system, which consists of cell bodies of neurons of the paraventricular and supraoptic nuclei, axons of the su-

${ }^{1}$ Abbreviations used in this paper: BNpI, bovine neurophysin I; CSF, cerebrospinal fluid; HNpI, human neurophysin I; PBS, phosphate-buffered saline. 
praoptic and paraventricular tracts, and axonal terminals in the infundibular process (17). Microscopic studies using less specific staining have suggested an association of the paraventricular and supraoptic neurons with the ependymal lining surface of the third ventricle and, therefore, CSF (18-22). In the present study we have localized neurophysin in the specialized ependymal tanycytes of the ventral portion of the third ventricle at the level of the median eminence.

\section{METHODS}

Preparation of bovine neurophysin has been previously described, and the radioimmunoassay procedure for neurophysin has been detailed (23). Human and monkey neurophysin was measured by a similar radioimmunoassay using human neurophysin I provided by Doctors Cheng and Friesen and described elsewhere (24). Human neurophysin is used as both the radioactive tracer and the unlabeled neurophysin of the standard curve. Antiserum to bovine neurophysin $I$ is utilized in the human and monkey assays at a dilution of 1-2000. $25 \mathrm{pg}$ of human neurophysin causes a $10 \%$ reduction in the binding of radiolabeled neurophysin. Using $50 \mu \mathrm{l}$ of plasma or CSF, we find that the assay readily measures neurophysin at concentrations as low as $0.5-0.6 \mathrm{ng} / \mathrm{ml}$. Human neurophysin I and II give parallel standard curves in this system using anti-bovine neurophysin I. Bovine neurophysin I and II also react with identity in this assay. All human and monkey neurophysin values reported here are a measure of "total" neurophysin with no distinction between different neurophysins. $50 \mu 1$ of normal human plasma from a well-hydrated male is added to each tube of the standard curve and to the CSF assay tubes to negate the effects of protein in comparing plasma with the standard curve or CSF with plasma. When $50 \mu 1$ of this normal human plasma is compared with a standard curve run in buffer alone, less than $0.6 \mathrm{ng} / \mathrm{ml}$ neurophysin is measured in the normal plasma. All samples were run at two dilutions and in duplicate or triplicate. Monkey neurophysin in plasma and CSF reacted identically with human neurophysin in this assay and is expressed in terms of the human neurophysin standard.

Human CSF and plasma was obtained following lumbar puncture during routine diagnostic procedures. Local lumbar anesthesia was used. CSF and plasma was obtained from five normal female Rhesus monkeys at various times of the menstrual cycle. CSF was obtained by cisternal or lumbar puncture in monkeys under phencyclidine tranquilization. The studies involving dogs were conducted in mongrel animals anesthetized with intravenously-administered pentobarbital. $60 \mathrm{~min}$ after induction of anesthesia, the dogs were injected intravenously with $375 \mu \mathrm{g}$ of a crude bovine neurophysin or with $50-100 \mu \mathrm{g}$ of purified bovine neurophysin I, and several plasma samples were taken over the next 75$105 \mathrm{~min}$. CSF was obtained by cisternal puncture. Unlike the human and monkey samples, the canine CSF and plasma samples were assayed by a specific bovine neurophysin I assay. This assay uses bovine neurophysin I and anti-neurophysin I at a dilution of $1: 35,000$ (23). At this antibody dilution the injected bovine neurophysin is measured while the dogs' own neurophysin is not detectable. Other dogs studied in the same way were injected with $10 \mathrm{ml}$ of $0.15 \mathrm{M} \mathrm{NaCl}$ rather than neurophysin. These animals served as controls.
Column chromatography of concentrated CSF specimens was done on G-75 Sephadex columns $(1 \times 25 \mathrm{~cm})$, and the elution patterns were compared with that of ${ }^{131}$ I-labeled human neurophysin I. Protein determinations were done by the Folin method of Lowry, Rosenbrough, Farr, and Randall (25).

Cross-sections of paraffin-embedded hypothalamic tissue from two adult female Rhesus monkeys (M210, M212) were prepared and stained by an immunoperoxidase technique as previously reported (17). The brain of M210 was prepared on day 14 of the menstrual cycle using perfusion fixation with $10 \%$ buffered formalin whereas M212 was prepared on day 35 of the menstrual cycle by immersion fixation in Bouin's solution. 5- $\mu \mathrm{m}$ paraffin sections on glass slides were deparaffinized, rehydrated in $0.01 \mathrm{M} \mathrm{pH} 7.2$ phosphate-buffered saline (PBS), and reacted in a threelayer immunoperoxidase bridge system to localize the antigenic tissue sites of neurophysin $(26,27)$. Rabbit antiserum to bovine neurophysin I $(1: 100)$ was first applied to the tissue sections as the specific antibody and incubated in a moist chamber for $30 \mathrm{~min}$. After washing for $10 \mathrm{~min}$ in $\mathrm{PBS}$, ovine antiserum to rabbit globulin and rabbit antiserum to horseradish peroxidase were sequentially applied in a similar fashion for $30 \mathrm{~min}$ each, followed by incubation with horseradish peroxidase $(0.5 \mathrm{mg} / \mathrm{ml})^{2}$ for $20 \mathrm{~min}$. 10 min washes in PBS were made between each step. The slides in which horseradish peroxidase was attached to antibody sites were reacted with $3,3^{\prime}$ diaminobenzidene $(75 \mathrm{mg} /$ $\mathrm{ml}$ ) with $0.003 \%$ hydrogen peroxide for $20 \mathrm{~min}$ to produce a brown color. Control experiments were performed by replacing specific rabbit antiserum to bovine neurophysin I with normal rabbit serum and with rabbit antiserum to bovine neurophysin I preabsorbed with bovine neurophysin I.

\section{RESULTS}

Similarity of pituitary and CSF neurophysin. The identity of CSF with pituitary neurophysin was established by column chromatography and by specific radioimmunoassay. The characteristic elution pattern of $\left[{ }^{181} \mathrm{I}\right]$ human neurophysin from a column of G-75 Sephadex $(1 \times 20 \mathrm{~cm})$ is shown in the top graph of Fig. $1.10 \mathrm{ml}$ of CSF from three patients was lyophilized to dryness and redissolved in $1 \mathrm{ml}$ of distilled water. The reconstituted CSF was applied to a Sephadex column and eluted with $0.05 \mathrm{M}$ phosphate buffer. The neurophysin content of the eluate was determined by radioimmunoassay. The elution pattern for CSF neurophysin was similar to [ $\left.{ }^{131} \mathrm{I}\right]$ pituitary neurophysin (Fig. 1, lower graph, line A). Line $B$ is a similar elution pattern of CSF neurophysin prepared from $10 \mathrm{ml}$ of spinal fluid from two patients. Again, the similarity between the elution of CSF neurophysin and pituitary neurophysin is noted. Of the total protein added to the columns $88 \%$ was eluted before and $8 \%$ after the neurophysin peaks. The salt peaks were eluted after the neurophysin. Each neurophysin peak containing $6 \%$ of the CSF protein and none of the CSF electrolytes was pooled and concentrated by ultrafiltration for further studies.

${ }^{2}$ Sigma Type VI, Sigma Chemical Co., St. Louis, Mo. 

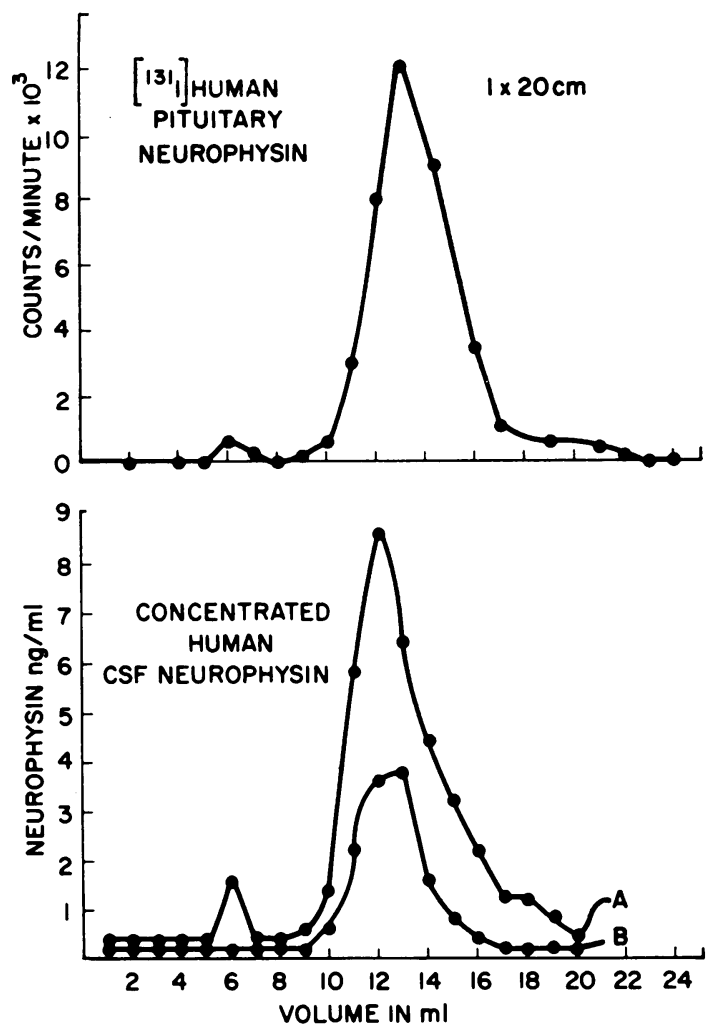

Figure 1 G-75 Sephadex chromatography of ${ }^{131}$ I-labeled human pituitary neurophysin (top) and two pools of concentrated human cerebrospinal fluid (bottom). $90 \%$ of the protein in CSF as determined by Folin is in the void volume 5-8 $\mathrm{ml}$. The CSF neurophysin as determined by radioimmunoassay has a peak similar to pituitary neurophysin. Pool A is $10 \mathrm{ml} \mathrm{CSF}$ from three patients and Pool B is $10 \mathrm{ml} \mathrm{CSF}$ from two patients.

Additional evidence for the identity of CSF neurophysin with pituitary neurophysin was obtained by adding each concentrate to a standard radioimmunoassay and demonstrating that both CSF neurophysin samples completely displaced $\left[{ }^{131} \mathrm{I}\right]$ pituitary neurophysin from the specific anti-neurophysin antibody. The neurophysin determinations of seven individual CSF samples run in one assay are illustrated with a solid line connecting the two dilutions of each sample (Fig. 2). These can be seen to approximate closely the curve of human pituitary neurophysin shown by the dotted line. Similar results were obtained in other assays.

Neurophysin levels in plasma and CSF. CSF specimens from 68 persons had a mean neurophysin value of $5.4 \mathrm{ng} / \mathrm{ml} \pm 0.30 \mathrm{SEM}$. The records of these patients were examined: 31 had no disease (negative evaluation for headache, low back pain, etc.) ; 9 had spinal nerve root compression; 3 had pituitary tumors; 24 had neurologic disease (seizure disorder, cerebrovascular accident, or brain tumor). There was no signifi- cant difference between mean neurophysin values in CSF from any of these groups, and no correlation between CSF neurophysin and total protein. The concentration of neurophysin in CSF was significantly different from the plasma neurophysin levels in healthy ambulatory adults in which the neurophysin concentration was $0.69 \pm 0.04 \mathrm{ng} / \mathrm{ml}(n=259 ; P<0.001$ by the unpaired $t$ test). Plasma and CSF neurophysin concentrations were determined simultaneously $( \pm 1 \mathrm{hr})$ in 5 monkeys and 13 humans (Fig. 3). In every case, the neurophysin concentration in CSF was greater than the neurophysin concentration in plasma from the same donor. The differences were highly significant $(P<0.001$ by the paired $t$ test). (Cisternal and lumbar CSF neurophysin concentrations were not significantly different.)

Source of neurophysin in CSF. As neurophysin is known to be secreted into plasma the transfer of neurophysin from plasma to CSF was investigated in mongrel dogs injected intravenously with bovine neurophysin. (Bovine neurophysin was used because it is available in greater quantity and can be specifically measured by radioimmunoassay.) We were able to follow the in jected protein independent of any changes in the dogs' own neurophysin. During the control period of $60 \mathrm{~min}$, plasma neurophysin was immeasurable in all animals. In two dogs injected with a bolus of $0.15 \mathrm{M} \mathrm{NaCl}$ and from which blood samples were taken periodically for $120 \mathrm{~min}$ and a CSF specimen at 105 min, neurophysin was un-

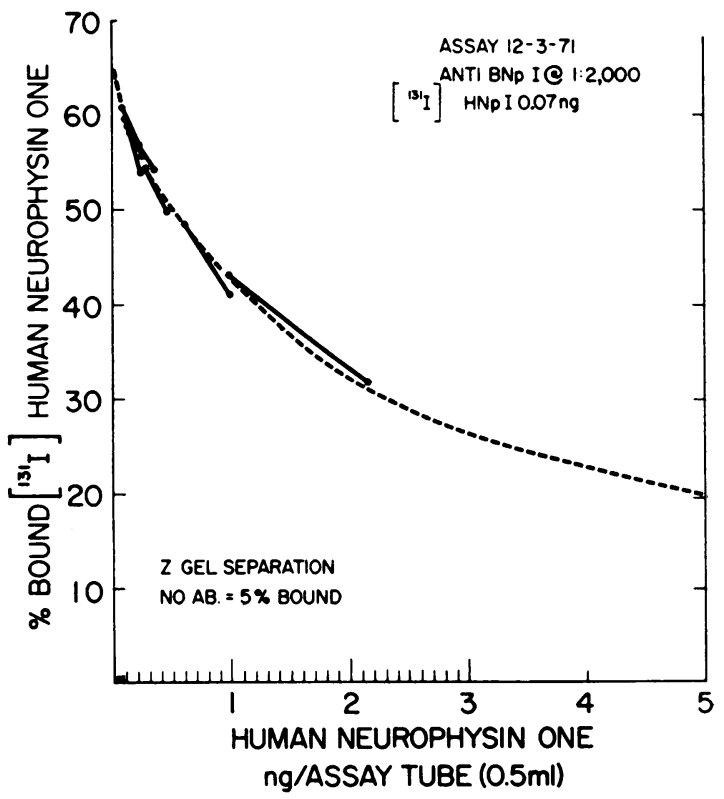

Figure 2 CSF neurophysin from seven patients run at two dilutions in the same assay. The dotted line is the standard curve using human pituitary neurophysin I ( $\mathrm{HNpI}$ ). The two dilutions of each sample are connected by a solid line and closely approximate the standard curve. 
detectable in all samples. Other dogs were similarly studied except that they were given a bolus of partially purified bovine neurophysin containing approximately $60 \%$ neurophysin I or purified bovine neurophysin I in $0.15 \mathrm{M}$ $\mathrm{NaCl}$. The blood and CSF levels of neurophysin I as determined by radioimmunoasay are shown in Table $I$. In five dogs which received partially purified bovine neurophysin, CSF was collected 75-105 min after the intravenous injection to allow time for transfer of neurophysin from plasma to CSF. However, the CSF neurophysin remained undetectable or very low in all animals in spite of the elevated plasma neurophysin concentrations. To determine if neurophysin might be crossing into CSF at a time earlier than anticipated, three dogs were studied by the same protocol but with earlier CSF sampling. These dogs were injected with purified bovine neurophysin I, and the results are shown in Table I ( $\operatorname{logss}^{6-8)} .30$ min after the injection of neurophysin, no neurophysin was detectable in the CSF.

Tissue localization of neurophysin. Monkey brains were examined to determine the anatomic association of neurophysin with CSF. Using the immunoperoxidase technique and light microscopy, we found that neurophysin was localized in certain hypothalamic structures of both monkeys. Neurophysin can be identified by heavy staining of the tracts from the supraoptic and paraventricular nuclei (Fig. 4; T), in the ependymal tanycytes (lower ventricle arrow), and in the external palisade layer (lower left arrow) of the median eminence. At this level in the hypothalamus the paraventricular and supraoptic tracts are joined and pass as a single tract (supraoptico-hypophyseal tract) through the median eminence to the infundibulum and posterior pituitary. Some fibers of the supraoptico-hypophyseal tract

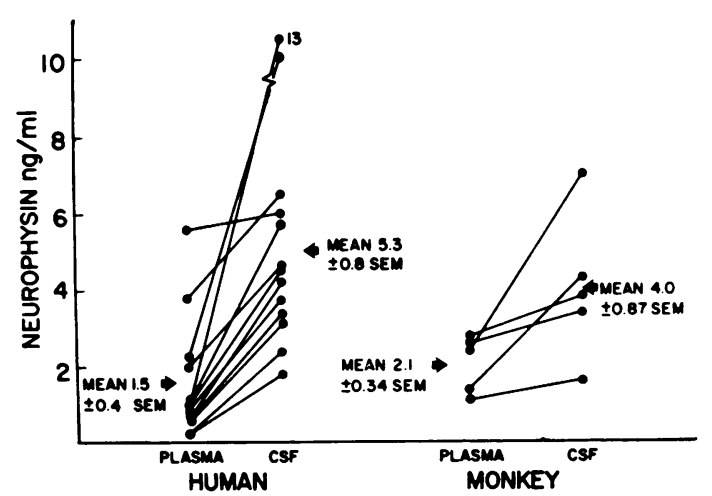

Figure 3 Simultaneous plasma and CSF neurophysin in 13 humans and 5 monkeys. Each plasma neurophysin concentration is connected to its CSF neurophysin concentration by a solid line.

pass near the wall of the third ventricle (Fig. 4: V). In adjacent sections (not shown here) some of these fibers appear to terminate at the ependymal layer of the third ventricle. In sections of every level of the median eminence, neurophysin is identified in the external layer, thus, localizing neurophysin to the zone where the axons of neurosecretory cells and the terminals of tanycytes contact the portal capillaries. The specificity of this staining is demonstrated by the lack of black stain in the ciliated ependyma in the upper third ventricle (Fig. 4); upper ventricular arrow) and by the absence of staining in control slides when normal rabbit serum or antiserum absorbed with neurophysin $I$ is substituted for the antiserum to neurophysin (Fig. 5).

At higher magnification, the specialized ependymal tanycyte (Fig. 6) shows intense staining in the perikaryon and on the ventricular surface, at times appear-

TABLE I

Effect of Intravenous Neurophysin on Plasma and CSF Neurophysin

\begin{tabular}{|c|c|c|c|c|c|c|c|c|c|c|c|c|c|c|c|c|c|}
\hline \multirow{2}{*}{\multicolumn{2}{|c|}{ Time }} & \multicolumn{2}{|c|}{ Dog 1} & \multicolumn{2}{|c|}{ Dog 2} & \multicolumn{2}{|c|}{$\operatorname{Dog} 3$} & \multicolumn{2}{|c|}{$\operatorname{Dog} 4$} & \multicolumn{2}{|c|}{$\operatorname{Dog} 5$} & \multicolumn{2}{|c|}{ Dog 6} & \multicolumn{2}{|c|}{ Dog 7} & \multicolumn{2}{|c|}{ Dog 8} \\
\hline & & Plasma & $\mathrm{CSF}$ & Plasma & CSF & Plasma & $\mathrm{CSF}$ & Plasma & $\mathrm{CSF}$ & Plasma & CSF & Plasma & $\mathrm{CSF}$ & Pla:ma & $\mathrm{CSF}$ & Pla:ma & $\mathrm{CSF}$ \\
\hline-60 & $\min$ & $<0.4$ & & $<0.4$ & & $<0.4$ & & $<0.4$ & & $<0.4$ & & $<0.4$ & & $<0.4$ & & $<0.4$ & \\
\hline-40 & $"$ & $<0.4$ & & $<0.4$ & & $<0.4$ & & $<0.4$ & & $<0.4$ & & $<0.4$ & & $<0.4$ & & $<0.4$ & \\
\hline $\begin{array}{r}-20 \\
0\end{array}$ & "' & $<0.4$ & & $<0.4$ & & $<0.4$ & & $<0.4$ & & $<0.4$ & & $<0.4$ & & $<0.4$ & & $<0.4$ & \\
\hline 2 & " & 115.0 & & 122.0 & & 63.0 & & 103.0 & & 105.0 & & 65.0 & & 37.0 & & 28.0 & \\
\hline 5 & $\prime \prime$ & 79.0 & & 48.0 & & 35.0 & & 54.0 & & 67.0 & & 39.0 & & 18.0 & & 12.0 & \\
\hline 15 & " & 25.0 & & 35.0 & & 16.0 & & 21.0 & & 20.0 & & 14.0 & & 7.0 & & 4.0 & \\
\hline 30 & $"$ & 14.0 & & 10.8 & & 5.2 & & 16.4 & & 17.6 & & 6.0 & $<0.4$ & 3.0 & 0.5 & & $<0.4$ \\
\hline 45 & " & 5.0 & & 5.0 & 0.5 & 0.6 & & 1.2 & & 4.0 & & 3.8 & & 1.4 & & 1.2 & \\
\hline 75 & $"$ & 0.8 & & & & 0.6 & $<0.4$ & 1.0 & $<0.4$ & 1.8 & 0.5 & 1.6 & & 0.8 & & 0.6 & $<0.4$ \\
\hline 105 & $" \prime$ & 0.4 & $<0.4$ & & & & & & & & & 1.2 & & 0.7 & & & \\
\hline
\end{tabular}

All numbers are bovine neurophysin $\mathrm{I}(\mathrm{BNpI})$ in nanograms per milliliter. Neurophysin was injected at 0 min. Dogs 1-5 received $375 \mu \mathrm{g}$ of crude bovine neurophysin containing approximately $60 \%$ BNpI. Dog 6 received $100 \mu \mathrm{g}$ and dogs 7 and 8 $50 \mu \mathrm{g}$ of purified $\mathrm{BNpI}$. 


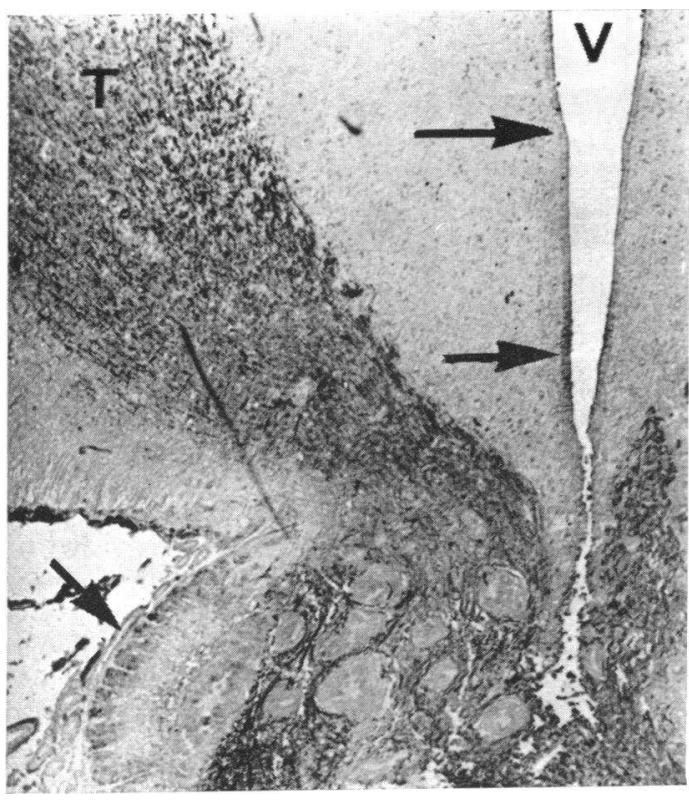

FIGURE 4 Low power photomicrograph of a cross-section of monkey 212 hypothalamus at the level of the median eminence. By immunoperoxidase method, neurophysin is localized in the supraoptico-hypophyseal tract ( $\mathrm{T})$, and in tanycytes of the basal ependyma (lower arrow at ventricle) and in the external palisade, layer of the median eminence (lower left arrow). More dorsal, ciliated ependyma contain little neurophysin (upper arrow). Artifacts include a tissue foldline between lower arrows and a tear at the ventricle base. $(\times 43)$

ing as globular protrusions. The cytoplasmic neurophysin streaks laterally from the perikaryon for a short distance in the tanycyte process which runs perpendicular to the ventricular surface (arrow Fig. 6). Neurophysin in the lateral tanycyte cannot be traced with certainty beyond that shown in the figure. The tanycytes contrast markedly with the ciliated ependymal cells of the dorsal portions of the third ventricle which show little staining (Fig. 7) and thus presumably contain little neurophysin.

\section{DISCUSSION}

Our studies demonstrate that neurophysin is present in CSF of man and monkey. CSF neurophysin has been concentrated and shown by column chromatography to have a molecular weight similar to pituitary neurophysin. The parallel behavior of CSF neurophysin and pituitary neurophysin in the radioimmunoassay and the ability of concentrated CSF neurophysin to inhibit the binding of pituitary neurophysin by specific antibodies to neurophysin demonstrate the immunologic identity of CSF and pituitary neurophysin in man.

The average concentration of neurophysin in CSF was unexpectedly much higher than that of plasma. Several reports have demonstrated that the vasopressin content in CSF is much less than that of plasma. CSF specimens from the rabbit (14), dog (16), and man (15) obtained in the resting state contain much lower vasopressin than the corresponding plasma specimens. When vasopressin release was stimulated by hemorrhage CSF vasopressin increased, but the peak CSF value was only $15 \%$ (16) or $25 \%$ (14) of the peak plasma value. Therefore, one would not have predicted the high neurophysin values in CSF. Yet, in every situation where

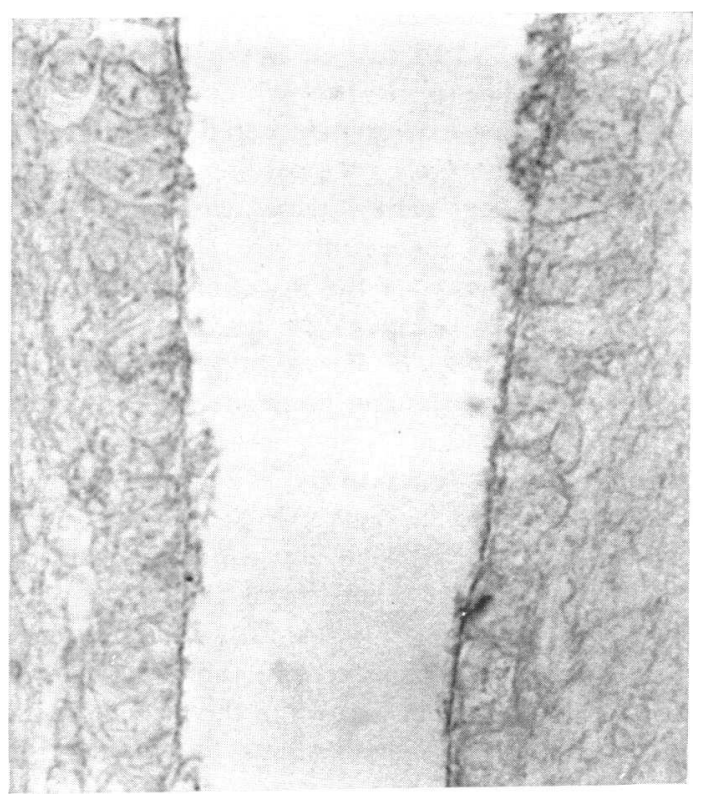

FIGURE 5 Higher magnification of an area corresponding to lower ventricle arrow of Fig. 4. Control experiment in which antibody to neurophysin is replaced with nonimmune rabbit serum. No neurophysin staining is seen and a faint general background remains. $(\times 504)$

paired plasma and CSF samples were taken from man or monkey, the concentration of neurophysin was higher in CSF than in plasma. Neurophysin is known to be secreted into plasma, but this finding of higher levels of neurophysin in CSF suggests that neurophysin is also secreted into CSF.

The possibility of neurophysin transfer from plasma to CSF was investigated by the infusion of bovine neurophysin in the dog. The assumption that the bovine neurophysin behaves physiologically like dog neurophysin is justified by the studies of Fawcett, Powell, and Sachs (28) who demonstrated that dog neurophysin possessed chemical and serologic properties similar to bovine neurophysin. Furthermore, the studies of Capra, Kehoe, Kotelchuck, Walter, and Breslow (29) demonstrated the close amino acid sequence of neurophysins from different species, and several investigators (28-31) have pointed out the immunologic cross-reactivity between 
species. Indeed, our antiserum to bovine neurophysin at low dilution (e.g., $1: 2000$ in a radioimmunoassay) binds with neurophysin from other species but does not bind at high dilution (e.g., 1:35,000). This fact enabled us to discriminate between bovine and canine neurophysins. When bovine neurophysin was injected into dogs in quantities sufficient to cause transient plasma neurophysin values that were $30-100$ times the normal resting value (3), virtually no bovine neurophysin appeared in CSF. This was true in the dogs injected with the crude neurophysin preparation as well as in dogs injected with purified bovine neurophysin I. This finding is further indication that the neurophysin present in CSF of monkey and man is the result of secretion of neurophysin into CSF. If neurophysin secretion and hormone secretion are mutually dependent phenomenon, then these data indicate that vasopressin is also secreted into CSF.

The anatomic localization of neurophysin in the monkey extends the observations of Talanti and Kivalo

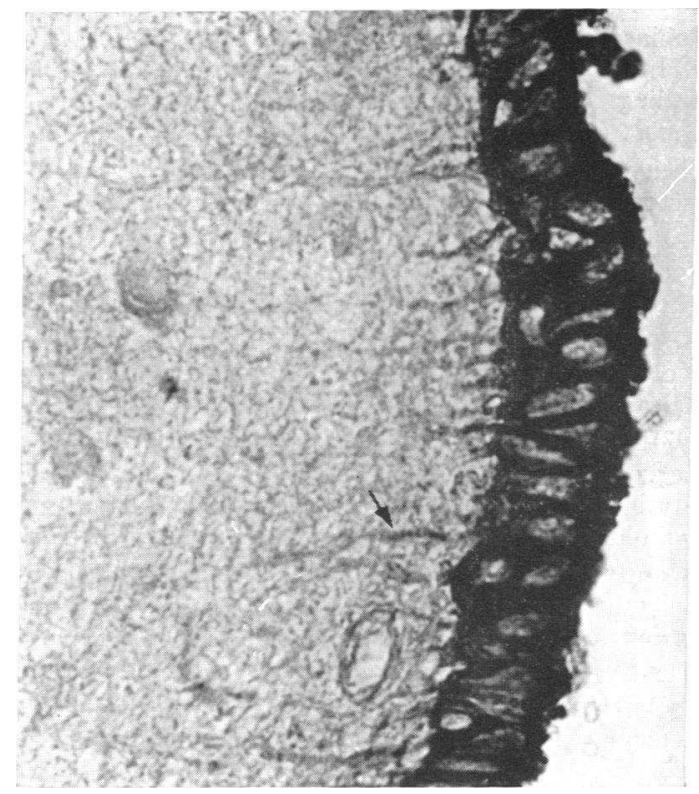

FigURE 6 Neurophysin staining of the area shown in Fig. 5 . Note the large amount of neurophysin on the ventricular surface and in the cytoplasm of tanycyte perikarya. Neurophysin staining fades as it streaks laterally in the process of the tanycyte (arrow). ( $\times 504)$

(32) in the camel. Using the less specific Gomori stain, he demonstrated neurosecretory material in fibers extending to the third ventricle and showed that these fibers separated from the supraoptico-hypophyseal tract which extends to the posterior pituitary. Our findings of neurophysin localization around the infundibular recess indicate that the "neurosecretory material" contains neurophysin. We also found staining where fibers from the supraoptico-hypophyseal tract approach the third ventricle suggesting that this may be a point of secretion of neurophysin into ventricular CSF. The infundibular area where neurophysin is concentrated in the tanycytes is receiving increasing attention by neuroendocrinologists independent of any consideration of vasopressin and oxytocin. Indeed, although there is strong evidence linking neurophysin with vasopressin and oxytocin in the posterior pituitary, it is possible that the secretion of neurophysin into CSF is independent of these hormones.

The tanycytes of the infundibular recess which we have shown to contain neurophysin are of specific anatomic interest. The studies of several investigators (3338) suggest that these specialized ependymal cells may play a neuroendocrine role by providing a pathway from the CSF of the third ventricle to the hypothalamic portal system. It has been shown that vasopressin placed in the third ventricle of the dog had a significant effect on adrenocortical steroid output (presumably by stimulating the release of $\mathrm{ACTH}$ ) whereas 10 times that dose by peripheral vein had no effect (35). Furthermore, peroxidase ( $\mathrm{mol} \mathrm{wt} \mathrm{42,000)}$ when injected into the third ventricle of a quail or rat is readily taken up by tanycyte cells and transported down their processes (34). Thus, a protein four times as heavy as neurophysin can be absorbed from CSF by tanycytes and transported out the tanycyte processes. Knowles and Kumar $(33,36)$ have traced the tanycyte processes from the surface of the third ventricle to their termination in close proximity

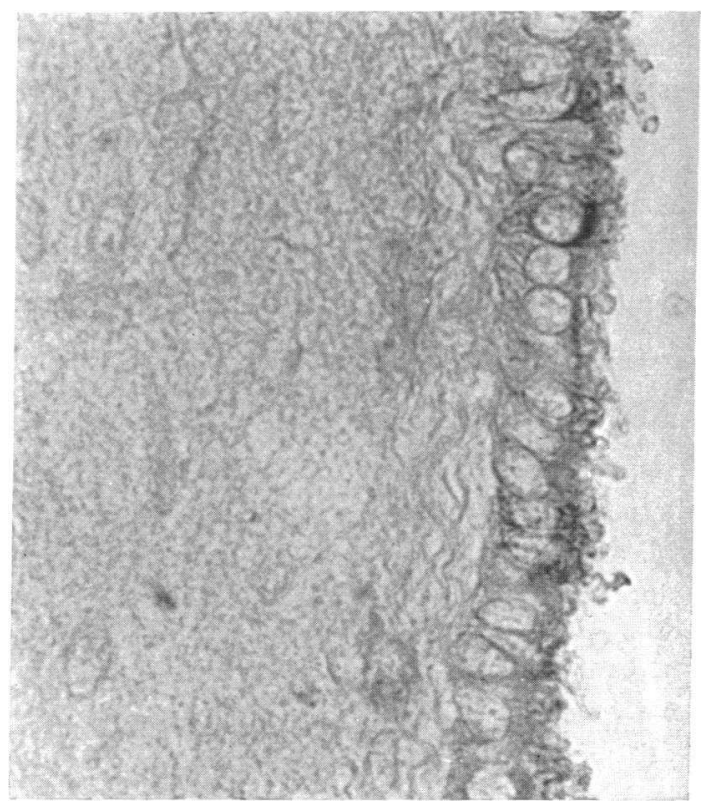

Figure 7 Ciliated ependyma of the same section shown in Fig. 6 (area of upper arrow at ventricle, Fig. 4) generally lack neurophysin. A small amount is seen in a few of these cells. $(\times 504)$ 
to the pericapillary space of the blood vessels of the pituitary portal plexus. These terminal processes are part of the outer palisade-contact zone of the median eminence. This zone is thought to be the site of delivery of releasing hormones to the portal vessels. While bidirectional flow in tanycytes has been considered. The microscopic appearance of their distal terminals is thought to be most consistent with terminal secretion $(36,37)$.

Our studies demonstrate the specific presence of neurophysin in the $\mathrm{CSF}$, in the tanycytes of the infundibular recess, in the tanycyte processes, and in the external palisade layer of the median eminence. This area around the third ventricle is the only area adjacent to the ventricular system which contains neurophysin, and we propose that fibers of the supraoptico-hypophyseal tract may secrete neurophysin into the CSF at this level. The intense staining of the ventricular surface of the tanycytes and the identification of neurophysin in the tanycyte processes suggests that these cells may absorb neurophysin from the CSF. This interpretation is most compatible with previous studies of tanycyte function. While our study has not specifically identified neurophysin in the distal terminals of the tanycyte processes, we have localized neurophysin in the external palisade layer of the median eminence where the tanycyte processes are known to abut onto portal vessels. While some neurophysin in this external layer may arrive from axons of the supraopticohypophyseal tract, it is likely that neurophysin is also present in the terminals of the tanycyte processes.

This paper is the first report of neurophysin in CSF and in areas of the brain separate from the supraoptic and paraventricular nuclei and their classic pathways to the neurohypophysis (20). The specific presence of neurophysin in CSF and the probability of its direct secretion supports the bioassay reports of vasopressin in spinal fluid. However, the more significant finding may be the localization of neurophysin around the infundibular recess of the third ventricle in the tanycytes, and around portal vessels. This area has been of interest as an alternate pathway for the secretion of anterior pituitary releasing factors (37). It has been suggested that releasing factors may first be secreted into CSF, reabsorbed by tanycytes, transported by their processes, and resecreted into the portal blood (38). The radioimmunoassay data on neurophysin in CSF and the anatomic findings are compatible with a similar concept for neurophysin. Whether this is an undescribed pathway of vasopressin and oxytocin secretion and/or whether neurophysin is related to the previous work on releasing factors remains to be determined.

\section{A. G. Robinson and E. A. Zimmerman}

\section{ACKNOWLEDGMENTS}

The aid and counsel of Doctors Konrad C. Hsu, Andrew G. Frantz, Myron Tannenbaum, and Peter W. Carmel was of invaluable assistance. Dr. Tannenbaum's help with the photography was of special importance. The International Institute for the Study of Human Reproduction, Columbia University, supplied animals from their monkey colony. Miss Linda Tolstoi and Ms. Barbara Brenneman gave technical and secretarial help.

These studies were supported by Health Research and Services Foundation of Pittsburgh, Grant no. 0-62 and by National Institutes of Health Grants NS-02005, AM 13200, and AM 14928.

\section{REFERENCES}

1. Acher, R., J. Chauvet, and G. Olivry. 1956. The actual existence of a single pituitary hormone. I. Relation between the oxytocin, vasopressin, and Vay Dyke's protein extracted from bovine pituitary. Biochim. Biophys. Acta. 22: 421.

2. Sachs, H., P. Fawcett, Y. Takabatake, and R. Portanova. 1969. Biosynthesis and release of vasopressin and neurophysin. Recent Prog. Horm. Res. 25: 447.

3. Robinson, A. G., E. A. Zimmerman, and A. G. Frantz. 1971. Physiologic investigation of the posterior pituitary binding proteins neurophysin I and neurophysin II. Metab. (Clin. Exp.). 20: 1148.

4. Cheng, K. W., and H. G. Friesen. 1970. Physiological factors regulating secretion of neurophysin. Mctab. (Clin. Exp.). 19: 876.

5. Forsling, M. L., M. J. Martin, and A. M. Burton. 1971. The effect of hydration on vasopressin and neurophysin release in the rat. J. Endocrinol. 51: 413.

6. McNeilly, A. S., J. J. Legros, and M. L. Forsling. 1972. Release of oxytocin vasopressin and neurophysin in the goat. J. Endocrinol. 52: 209.

7. Legros, J. J., and P. Franchimont. 1972. Human neurophysine blood levels under normal experimental and pathological conditions. Clin. Endocrinol. 1: 99.

8. Dean, C. R., D. B. Hope, and T. Kazic. 1968. Evidence for the storage of oxytocin with neurophysin I and of vasopressin with neurophysin II in separate neurosecretory granules. Br. J. Pharmacol. 34: 192.

9. LaBella, F. S. 1968. Storage and secretion of neurohypophyseal hormones. Can. J. Physiol. Pharmacol. 46: 335.

10. Cheng, K. W., and H. G. Friesen. 1971. Isolation and characterization of a third component of porcine neurophysin. J. Biol. Chem. 246: 7656.

11. Burford, G. D., C. W. Jones, and B. T. Pickering. 1971. Tentative identification of a vasopressin-neurophysin and an oxytocin-neurophysin in the rat. Biochem. J. 124: 809 .

12. Heller, $H$. Neurohypophyseal hormone in the cerebrospinal fluid. In Zirkumventrikulare Organe und Liquor. G. Sterba, editor. Gustav Fischer Verlag, Germany, 235.

13. Van Dyke, H. B. 1936. The Physiology and Pharmacology of the Pituitary Body, University of Chicago Press, Chicago, Ill. 1: 333 .

14. Heller, H., S. H. Hasan, and A. Q. Saifi. 1968. Antidiuretic activity in the cerebrospinal fluid. J. Endocrinol. $41: 273$. 
15. Gupta, K. K. 1969. Antidiuretic hormone in cerebrospinal fluid. Lancet. 1: 581.

16. Vorherr, H., M. W. B. Bradbury, M. Hoghoughi, and C. R. Kleeman. 1968. Antidiuretic hormone in cerebrospinal fluid during endogenous and exogenous changes in its blood level. Endocrinology. 83: 246.

17. Zimmerman, E. A., K. C. Hsu, A. G. Robinson, P. W. Carmel, A. G. Frantz, and M. Tannenbaum. 1973. Studies of neurophysin secreting neurons with immunoperoxidase techniques employing antibody to bovine neurophysin I. Light microscopic findings in monkey and bovine tissues. Endocrinology. 92: 931.

18. Bargmann, W. 1953. Uber das Zwischenhirn-hypophysensytem von fischen. Z. Zellforsch. 38: 275.

19. Hild, W. 1951. Vergleichende untersuchungen uber neurosekretion im zwischenhirn der amphibien and reptilien. Z. Anat. Entwicklungsesch. 115.

20. Bargmann, W., and E. Scharrer. 1951. The site of origin of the hormones of the posterior pituitary. Am. Sci. 39: 255.

21. Stutinsky, F. 1953. La neurosecretion che l'anguille normale et hypophysectomisee. Z. Zellforsch. 39: 276

22. Smoller, C. G. 1964. Neurosecretory processes extending into third ventricle: secretory or sensory? Science (Wash. D. C.). 147: 882 .

23. Robinson, A. G., E. A. Zimmerman, E. G. Engleman, and A. G. Frantz. 1971. Radioimmunoassay of bovine neurophysin: specificity of neurophysin I and neurophysin II. Metab. (Clin. Exp.). 20: 1138.

24. Cheng, K. W., and H. G. Friesen. 1972. The isolation and characterization of human neurophysin. J. Clin. Endocrinol. Metab. 34: 165.

25. Lowry, O. H., N. J. Rosenbrough, A. L. Farr, and R. J. Randall. 1951. Protein measurement with the Folin phenol reagent. J. Biol. Chem. 193: 265.

26. Mason, T. E., R. F. Phifer, S. S. Spicer, R. A. Swallow, and R. B. Dreskin. 1969. An immunoglobulin-enzyme bridge method for localizing tissue antigens. J. Histochem. Cytochem. 17: 563.

27. Sternberger, L. A., P. H. Hardy, Jr., J. J. Cuculis, and H. G. Meyer. 1970. The unlabeled antibody enzyme method of immunohistochemistry. J. Histochem. Cytochem. 18: 315 .
28. Fawcett, C. P., A. E. Powell, and H. Sachs. 1968. Biosynthesis and release of neurophysin. Endocrinology. 83: 1299.

29. Capra, J. D., J. M. Kehoe, D. Kotelchuck, R. Walter, and E. Breslow. 1972. Evolution of neurophysin proteins: the partial sequence of bovine neurophysin $\mathrm{I}$. Proc. Natl. Acad. Sci. 69: 431.

30. Cheng, K. W., and H. G. Friesen. 1971. A radioimmunoassay for vasopressin binding proteins-neurophysin. Endocrinology. 88: 608.

31. Legros, J. J., and P. Franchimont. 1972. Radioimmunologic behavior of human and rat neurophysin as compared with bovine neurophysin I and II. Program of the IV International Congress of Endocrinology. Abstract 112.

32. Talanti, S., and E. Kivalo. 1961. The infundibular recess in the brain of Camelus dromedarius with particular reference to its neurosecretory pathways into the third ventricle. Expcrientia (Basel). 17: 470 .

33. Kumar, T. C. A., and F. G. W. Knowles. 1967. A system linking the third ventricle with the pars tuberalis of the rhesus monkey. Nature (Lond.). 215: 54.

34. Kobayashi, H. Median eminence of the hagfish and ependymal absorption in higher vertebrates. In BrainEndocrine Interaction; Median Emience: Structure and Function. K. M. Knigge, D. E. Scott, and A. Weindl, editors. Karger AG, Basel, Switzerland. 67.

35. Kwaan, H. C., and H. J. Bartlestone. 1959. Corticotropin release following injections of minute doses of arginine vasopressin into the third ventricle of the dog. Endocrinology. 65: 982.

36. Knowles, F., and T. C. A. Kumar. 1969. Structural changes related to reproduction in the hypothalamus and in pars tuberalis of the rhesus monkey. In The Royal Society of London, Philosophical Transactions B. 256: 357 .

37. Knigge, K. M., and D. E. Scott. 1970. Structure and function of the median eminence. Am. J. Anat. 129: 223.

38. Porter, J. C., R. S. Mical, P. R. Tippit, and J. W. Drane. 1970. Effect of selective surgical interruption of the anterior pituitary's blood supply on ACTH release. Endocrinology. 86: 590. 